\title{
Effects of graphene oxides on the cure behaviors of a tetrafunctional epoxy resin
}

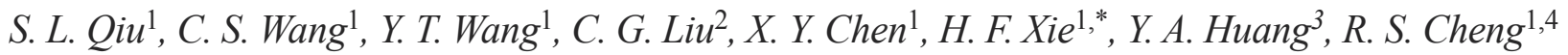 \\ ${ }^{1}$ Key Laboratory for Mesoscopic Chemistry of Ministry of Education, Department of Polymer Science and Engineering, \\ School of Chemistry and Chemical Engineering, Nanjing University, Nanjing 210093, China \\ ${ }^{2}$ Institute of Chemical Industry of Forest Products, Chinese Academy of Forestry, Key Open Lab of Forest Chemical \\ Engineering, State Forestry Administration, Nanjing 210042, China \\ ${ }^{3}$ School of Material Engineering, Nanjing Institute of Technology, Nanjing 211167, China \\ ${ }^{4}$ College of Material Science and Engineering, South China University of Technology, Guangzhou 510640, China
}

Received 21 January 2011; accepted in revised form 22 March 2011

\begin{abstract}
The influence of graphene oxides (GOs) on the cure behavior and thermal stability of a tetrafunctional tetraglycidyl-4,4'-diaminodiphenylmethane cured with 4,4'-diaminodiphenylsulfone was investigated by using dynamic differential scanning calorimetry (DSC) and thermogravimetric analysis (TGA). The dynamic DSC results showed that the initial reaction temperature and exothermal peak temperature decreased with the increase of GO contents. Furthermore, the addition of GO increased the enthalpy of epoxy cure reaction. Results from activation energy method showed that activation energies of GO/epoxy nanocomposites greatly decreased with the GO content in the latter stage, indicating that GOs significantly hindered the occurrence of vitrification. The oxygen functionalities, such as hydroxyl and carboxyl groups, on the surface of GOs acted as catalysts and facilitated the curing reaction and the catalytic effect increased with the GO contents. TGA results revealed that the addition of GOs decreased the thermal stability of epoxy.
\end{abstract}

Keywords: nanocomposites, thermal properties, thermosetting resin, graphene oxide, epoxy resin

\section{Introduction}

Epoxy resins are the most important thermosets, widely used as adhesives, coatings, and composite materials due to their low density, good thermal, electrical and mechanical properties. However, some advanced applications need further improvement of multifunctional properties, such as mechanical properties, thermal expansion, thermal and electrical conductivity. Therefore, reinforced fillers, such as carbon black, glass fibers and carbon fibers, have been incorporated into the resins [1].

As carbon-based nanofillers for epoxy nanocomposites, carbon nanotubes (CNTs) and carbon nanofibers (CNFs), which have small dimensions and high aspect ratios, have been received much atten- tion as fillers with potential for use in many applications due to their remarkable physical, chemical, and electrical properties. CNT- and CNF-reinforced epoxy nanocomposites have shown improved mechanical, electrical and thermal properties [2-5]. However, the high cost of CNTs and CNFs and the poor dispersion in the epoxy limits their range of practical applicability.

Currently, graphite oxides, which consists a layered structure of graphene oxide (GOs) sheets and can be completely exfoliated to produce aqueous colloidal suspension of GO sheets by simple sonication in aqueous and organic solvents, have received considerable amount of attention in the area of polymer nanocomposites due to their inexpensive

\footnotetext{
${ }^{*}$ Corresponding author, e-mail:hfxie@nju.edu.cn

(C) BME-PT
} 
and feasible substitute for CNTs and CNFs [6-10]. GOs, which have been demonstrated containing many epoxy groups [11], might make an ideal filler for epoxy resin which also contains epoxy groups, on the basis of the principle of dissolution in a similar material structure. Recently, Yang et al. [12] prepared GO/epoxy nanocomposites through twophase extraction. Great improvements in mechanical properties such as compressive failure strength and toughness have been achieved for the chemically converted $\mathrm{GO} /$ epoxy resin for a $0.0375 \mathrm{wt} \%$ loading of chemically converted GO sheets in epoxy resin by 48.3 and $1185.2 \%$, respectively.

The study of the cure kinetics is of great importance in epoxy curing process. In particular, the study of the cure reactions of epoxy as a function of the processing conditions, from a kinetic point of view, is very important for the analysis and design of processing operations. Differential scanning calorimetry (DSC) may be considered as one of the most interesting techniques for kinetic analysis of cure reactions of thermosetting systems [13-15]. Numerous studies on cure kinetics of epoxy in presence of carbon-based nanofillers have been investigated [16-25]. Recently, Allaoui and El Bounia [16] had reviewed the influence of CNTs on the cure kinetics of epoxy resin. Our previous studies showed that the addition of CNTs could accelerate the cure reaction of epoxy resin, while CNFs had only a negligible effect on the cure kinetics of the epoxy [17, 18]. Abdalla et al. [19] investigated the effect of carboxyl and fluorine surface modification of multiwalled carbon nanotubes (MWCNTs) on the cure behavior of epoxy resins with the modified CNTs, and reported that the activation energy and rate constant were not affected by the fluorine modification whereas the resins with carboxylated MWCNTs exhibited an increase in the activation energy and a lower rate constant for the cure reaction. Zhou et al. [20-22] studied the effects of MWCNTs and carboxylic functionalization of MWCNTs on the cure reaction of epoxy. They reported that MWCNTs had an accelerating effect in the initial curing stage, whereas in the later curing stage, MWCNTs prevented from the occurrence of vitrification [20]. However, carboxylic functionalization of MWCNTs did not change the autocatalytic cure reaction mechanism of epoxy nanocomposites and had catalytic effect on the curing process [21, 22]. Jana and
Zhong [23] found that expanded graphite (EG) did not significantly impede the cure reaction of epoxy. Guo et al. [24] reported that at lower concentrations (1 phr) of EG, compared with the curing activation energy $\left(E_{\alpha}\right)$ of the neat epoxy resin, the composite with EG had a lower $E_{\alpha}$ before the gelation and a higher $E_{\alpha}$ after the gelation. At higher concentrations of EG, however, in the whole conversion range, the composite with EG showed a higher $E_{\alpha}$ compared with the neat epoxy resin.

The tetrafunctional epoxy resin tetraglycidyl-4,4'diaminodiphenylmethane (TGDDM) cured with the aromatic diamine 4,4'-diaminodiphenylsulfone (DDS), is one of the most widely employed matrices for the production of high performance fiber composites in the aircraft and spacecraft industries. The attractive features of this thermosetting resin are its low density combined with high tensile strength and modulus, and a very high glass transition temperature combined with good thermal and chemical resistance [26]. In present work, GO prepared with Hummers method was incorporated into the tetrafunctional epoxy systems as carbon-based nanofiller. Dynamic DSC was used to investigate the influence of GOs on the cure reaction of TGDDM/ DDS nanocomposites. Furthermore, the thermal stability and morphology of GO/epoxy nanocomposites were studied.

\section{Experimental \\ 2.1. Materials}

The epoxy resin used in this study was TGDDM, AG80, with a weight per epoxy equivalent of 120 g/equiv., from Shanghai Synthetic Resin Institute (Shanghai, China). The curing agent was DDS, with a molecular mass of 248.31 and purity $>99 \%$ according to the supplier, Petroleum and Chemical Factory of Fudan University (Shanghai, China). Natural graphite flakes, supplied by Guyu Graphite Co. Ltd. (Qingdao, China), is 80 mesh, equal to $250 \mu \mathrm{m}$.

\subsection{Sample preparation}

GO was obtained by harsh oxidation of the graphite flakes according to the Hummers method [27]. After purification, the product was put in a vacuum desiccator for a week. The final product was added to ethanol and sonicated until it became clear with no visible particulate matter. The suspension was 
then added to TGDDM resin and sonicated for $2 \mathrm{~h}$. Subsequently, the ethanol was evaporated off by heating the mixture on a magnetic stir plate using a Teflon-coated magnetic bar for $3 \mathrm{~h}$ at $70^{\circ} \mathrm{C}$. Next, the mixture was placed in a vacuum chamber for $12 \mathrm{~h}$ at $70^{\circ} \mathrm{C}$ to ensure that all of ethanol had been removed. Then, the mixture was placed in an oil bath at $120^{\circ} \mathrm{C}$ and a stoichiometric amount of DDS was slowly added, under continuous mechanical stirring, until a homogeneous mixture was observed which took about $10 \mathrm{~min}$. Several DSC aluminum pans were filled with the reaction mixture. The samples $(\sim 10 \mathrm{mg})$ were then cooled and stored in a freezer until required. The weight fractions of GOs in the TGDDM/DDS system were 1, 2 and 5 wt \%, respectively.

\subsection{Characterization}

The Fourier-transform infrared (FT-IR) spectra of the natural graphite flakes and GO were recorded on a Nicolet iS10 FT-IR spectrometer using the attenuated total reflectance (ATR) technique (Thermo Scientific, USA). The spectrum was scanned 64 times at a resolution of $4 \mathrm{~cm}^{-1}$.

The analyses of the X-ray photoelectron spectra (XPS) were carried out on a ESCALAB 250 X-ray photoelectron spectroscope (Thermo Scientific, USA) equipped with a monochromatic $\mathrm{Al} \mathrm{K}_{\alpha}$ $(1486.6 \mathrm{eV})$ source and a pass energy of $20 \mathrm{eV}$.

A Pyris 1 DSC (PerkinElmer, USA) was used for the dynamic curing experiments and data analysis under an argon flow of $20 \mathrm{ml} / \mathrm{min}$. The dynamic DSC experiments were conducted at heating rates of $2.5,5,10$, and $20^{\circ} \mathrm{C} / \mathrm{min}$ over a temperature range of $50-300^{\circ} \mathrm{C}$. The reaction was considered to be complete when the rate curve leveled off to a baseline. The total area under the exothermal curve, based on the extrapolated baseline at the end of the reac-

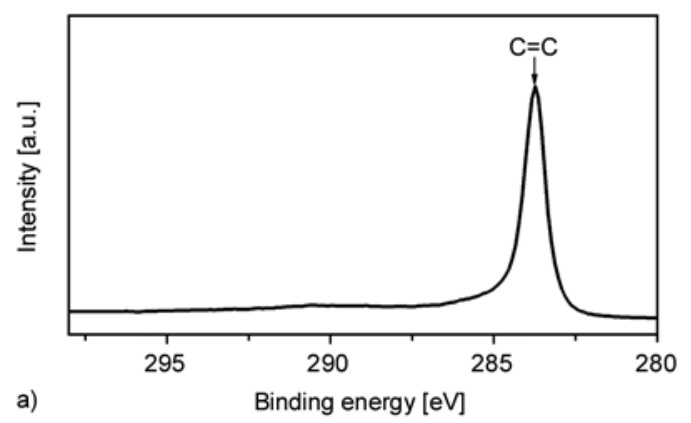

tion, was used to calculate the total heat of reaction, $\Delta H[\mathrm{~J} / \mathrm{g}]$.

Thermogravimetric analysis (TGA) was completed on a Pyris 1 TGA (Perkin Elmer, USA) with a heating rate of $20^{\circ} \mathrm{C} / \mathrm{min}$ under $\mathrm{N}_{2}$ atmosphere from 25 to $700^{\circ} \mathrm{C}$.

The fracture surfaces of samples were observed at $10 \mathrm{kV}$ with a field emission scanning electron microscopy (FE-SEM, Hitachi S-4800, Japan). The cured samples were fractured under liquid nitrogen, and then the fractured surfaces were vacuum-coated with a thin gold layer.

\section{Results and discussion \\ 3.1. Characterization of GOs}

The high degree of GO oxidation was confirmed by XPS: the survey spectra for pristine graphite and GO (not shown) yielded $\mathrm{C} / \mathrm{O}$ atomic ratios of 30.7 and 2.3, respectively. Figure 1 shows the C1s XPS spectra of the pristine graphite and GO. The narrow, asymmetric $\mathrm{C} 1 \mathrm{~s}$ band characteristic of pristine graphite (a) transforms into a complex band showing three maxima for GO (b), as expected, due to the high percentage of oxygen functionalities. The C1s XPS spectrum of graphene oxide (Figure 1b) clearly indicates a considerable degree of oxidation with three components that correspond to carbon atoms in different functional groups: the non-oxygenated ring $\mathrm{C}(284.5 \mathrm{eV})$, the $\mathrm{C}$ in $\mathrm{C}-\mathrm{O}$ bonds $(286.6 \mathrm{eV})$, and the carboxylate carbon $(\mathrm{O}-\mathrm{C}=\mathrm{O}$, $288.5 \mathrm{eV})$ [28].

The FT-IR spectra of the pristine graphite and GO are presented in Figure 2. The baselines of FT-IR spectra of conducting materials have a tendency to tilt. Since graphite is a conducting material, the baseline is slanted [15]. From the spectrum of pristine graphite it is obvious that there was a negligible amount of hydroxyl, $\mathrm{C}=\mathrm{O}$, or $\mathrm{C}-\mathrm{O}$ groups in the

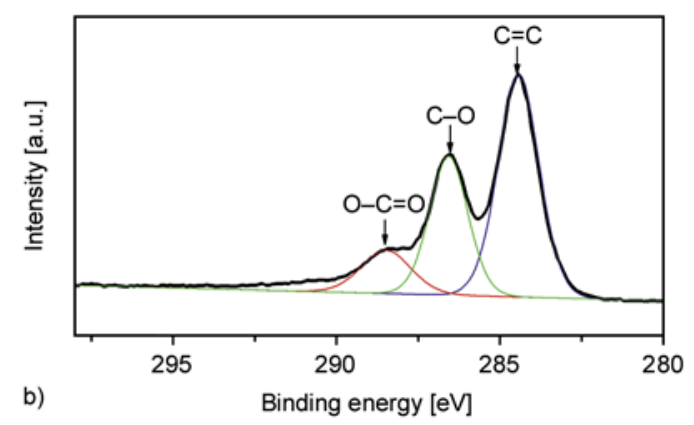

Figure 1. C1s XPS spectra for the pristine graphite (a) and GO (b) 


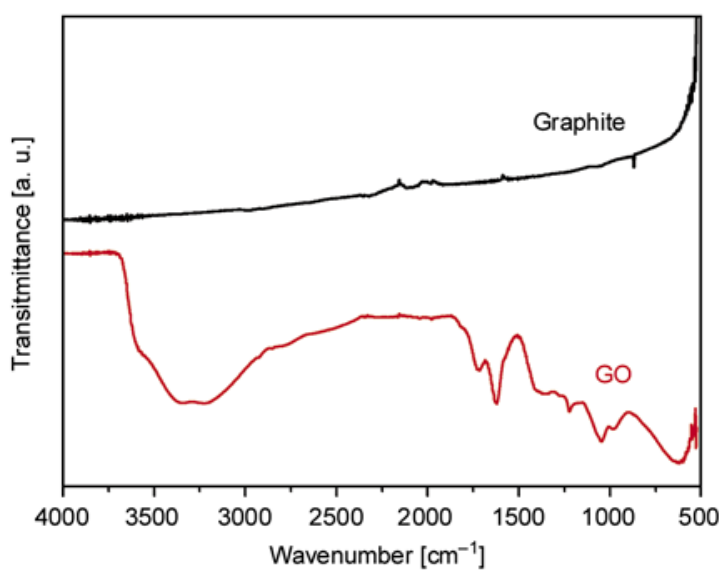

Figure 2. FT-IR spectra for the pristine graphite and GO

pristine graphite. The most prominent features in the spectrum of GOs are the adsorption bands corresponding to the $\mathrm{O}-\mathrm{H}$ stretching vibrations at $3428 \mathrm{~cm}^{-1}$, the $\mathrm{C}=\mathrm{O}$ carbonyl stretching at $1733 \mathrm{~cm}^{-1}$, the phenol $\mathrm{C}=\mathrm{C}$ ring stretching at $1621 \mathrm{~cm}^{-1}$, the $\mathrm{C}-\mathrm{O}$ stretching at $1053 \mathrm{~cm}^{-1}$, and the $\mathrm{C}-\mathrm{OH}$ stretching, presumably from phenols, at $1226 \mathrm{~cm}^{-1}$. Other researchers also observed similar functional groups $[11,28,29]$. Thus, similar to XPS, FTIR spectra provided the evidence of the presence of different types of oxygen functionalities on the GO material, which could affect the cure reaction of the epoxy resin.

\subsection{Effects of GOs on the cure reaction}

The dynamic DSC curves for the pure GO and GO/ TGDDM/DDS nanocomposites at a heating rate of $20^{\circ} \mathrm{C} / \mathrm{min}$ are shown in Figure 3. DSC of GO shows

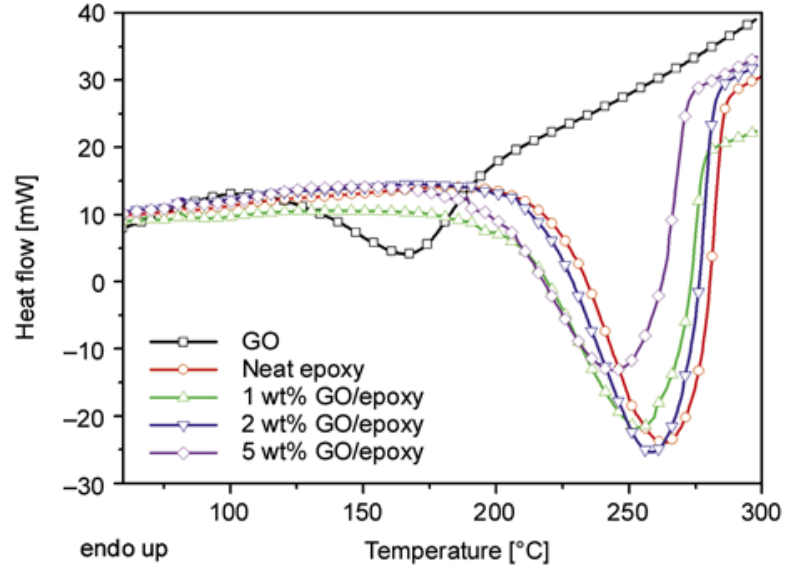

Figure 3. Dynamic DSC curves for neat epoxy and GO/ epoxy nanocomposites at a heating rate of $20^{\circ} \mathrm{C} / \mathrm{min}$

one strong extherthomic peak at $166^{\circ} \mathrm{C}$, which was caused by the decomposition of the organic groups on the $\mathrm{GO}$ sheets and evolution of $\mathrm{H}_{2} \mathrm{O}, \mathrm{CO}$ and $\mathrm{CO}_{2}$ [30]. It is obvious that $\mathrm{GO}$ has an accelerating effect on the curing process of TGDDM/DDS nanocomposites with a trend of cure reaction peaks towards lower temperatures. The initial reaction temperature $\left(T_{\mathrm{i}}\right)$, exothermal peak temperature $\left(T_{\mathrm{p}}\right)$ and $\Delta H$ of $\mathrm{GO} /$ epoxy nanocomposites at different heating rates are list in Table 1. It can be observed that both $T_{\mathrm{i}}$ and $T_{\mathrm{p}}$ decrease with the increase of GO contents, indicating that the GOs act as catalysts and facilitate the curing reaction and the catalytic effect increases with the GO contents. The enthalpies of GO/epoxy nanocomposites vary with the GO contents, if they are converted to average kilojoules

Table 1. The initial reaction temperature $\left(T_{\mathrm{i}}\right)$, exothermal peak temperature $\left(T_{\mathrm{p}}\right)$ and total heat of reaction $(\Delta H)$ of $\mathrm{GO} /$ epoxy nanocomposites at different heating rates

\begin{tabular}{|c|c|c|c|c|c|c|}
\hline $\begin{array}{c}\text { GO } \\
{[w t \%]}\end{array}$ & $\begin{array}{c}\text { Heating rate } \\
{\left[{ }^{\circ} \mathrm{C} / \mathrm{min}\right]}\end{array}$ & $\begin{array}{c}\mathbf{T}_{\mathbf{i}} \\
{\left[{ }^{\circ} \mathbf{C}\right]}\end{array}$ & $\begin{array}{c}\mathbf{T}_{\mathbf{p}} \\
{\left[{ }^{\circ} \mathbf{C}\right]}\end{array}$ & $\begin{array}{c}\Delta \mathbf{H} \\
{[\mathbf{J} / \mathbf{g}]}\end{array}$ & $\begin{array}{r}\overline{\Delta \mathbf{H}} \\
{[\mathbf{J} / \mathbf{g}]}\end{array}$ & $\begin{array}{c}\overline{\mathbf{Q}_{0}} \\
{[\mathrm{~kJ} / \mathrm{mol} \text { epoxide] }}\end{array}$ \\
\hline \multirow{4}{*}{0} & 2.5 & 155.4 & 196.5 & 629.5 & \multirow{4}{*}{658.6} & \multirow{4}{*}{120.7} \\
\hline & 5.0 & 161.2 & 213.1 & 651.9 & & \\
\hline & 10.0 & 162.9 & 234.8 & 653.5 & & \\
\hline & 20.0 & 173.4 & 262.8 & 699.5 & & \\
\hline \multirow{4}{*}{1} & 2.5 & 120.4 & 192.3 & 654.6 & \multirow{4}{*}{654.3} & \multirow{4}{*}{121.2} \\
\hline & 5.0 & 137.6 & 212.3 & 645.2 & & \\
\hline & 10.0 & 161.8 & 234.8 & 628.7 & & \\
\hline & 20.0 & 166.3 & 258.3 & 688.7 & & \\
\hline \multirow{4}{*}{2} & 2.5 & 135.0 & 189.4 & 660.0 & \multirow{4}{*}{660.1} & \multirow{4}{*}{123.5} \\
\hline & 5.0 & 137.1 & 210.8 & 669.9 & & \\
\hline & 10.0 & 142.7 & 230.8 & 645.1 & & \\
\hline & 20.0 & 161.3 & 253.4 & 665.5 & & \\
\hline \multirow{4}{*}{5} & 2.5 & 113.3 & 188.9 & 620.1 & \multirow{4}{*}{631.3} & \multirow{4}{*}{121.2} \\
\hline & 5.0 & 131.7 & 203.8 & 651.9 & & \\
\hline & 10.0 & 133.4 & 225.6 & 615.0 & & \\
\hline & 20.0 & 136.5 & 244.3 & 638.0 & & \\
\hline
\end{tabular}


per equivalent of epoxide $\left(\overline{Q_{0}}\right)$, it can be seen that the addition of GO increases the enthalpy of epoxy cure reaction. Furthermore, it can be also observed that no linear relationship of enthalpies between different contents of GO. The influence of carbonbased nano-fillers on the enthalpies of the epoxy cure reaction is different for different nanocomposites. The addition of CNTs [19, 20, 31] and EG [24] decreased the $\Delta H$ of epoxy, whereas CNF had no pronounced effect on the heat of the TGDDM/DDS cure reaction [32] and silanized and polyaniline modified CNFs increased the $\Delta H$ of epoxy [33,34]. It is believed that the addition of hydroxyl-containing compounds (water, alcohols, phenols, acids) considerably promoted the interaction of epoxy compounds with amines and other nucleophilic reagents [35]. In this case, the epoxy ring carbon atom became more sensitive to nucleophilic attack. The epoxy-oligomer curing with amines had an autocatalytic character due to the accumulation of hydroxyl groups during the reaction. According to recent studies [36], GOs have their basal planes decorated mostly with epoxide and hydroxyl groups, in addition to carbonyl and carboxyl groups located presumably at the edges (Lerf-Klinowski model), which agreed well with the results of XPS and FTIR discussed above. Gao et al. [37] proposed that GO contains ketones, 6-membered lactol rings, and tertiary alcohol in addition to epoxide and hydroxyl groups. Therefore, it can be concluded that these different types of oxygen functionalities on the surface of GOs are considered as catalysts to accelerate the cure reaction between epoxide and amine groups.

Figure 4 shows the conversions of reaction $(\alpha)$ as a function of temperature for neat epoxy and $\mathrm{GO} /$ epoxy nanocomposites at a heating rate of $20^{\circ} \mathrm{C} / \mathrm{min}$. It can be observed that all curves show a sigmoidal form, which indicates that the cure reaction of TGDDM/DDS system is autocatalytic in agreement with our previous studies $[17,18]$. Consequently, the incorporation of GOs has no influence on the cure reaction mechanism of the TGDDM/DDS system. Notably, from Figure 4, $\alpha$ of GO/epoxy composite increases with the GO contents and is higher than that of neat epoxy. These results further confirm that GOs act as catalysts in the cure reaction of epoxy and the catalytic effect increases with the GO contents.

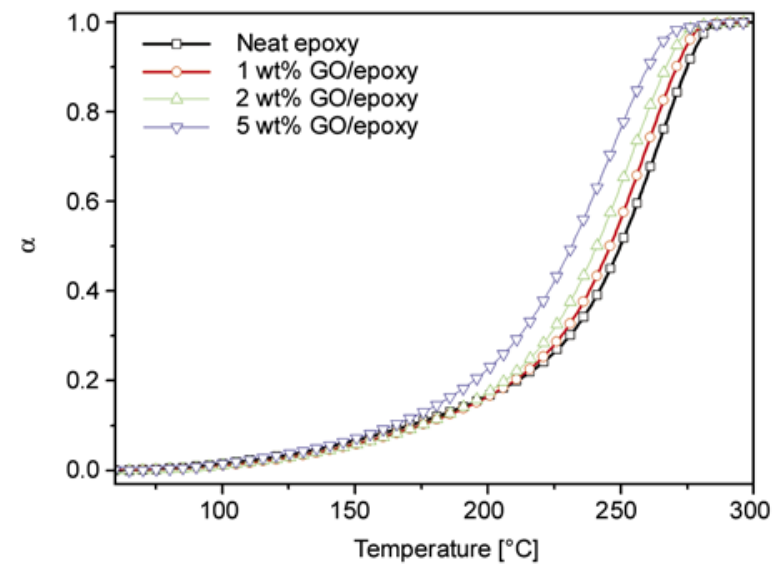

Figure 4. The conversions of reaction $(\alpha)$ as a function of temperature for neat epoxy and GO/epoxy nanocomposites at a heating rate of $20^{\circ} \mathrm{C} / \mathrm{min}$

\subsection{Effects of GOs on the activation energy}

To further investigate the effect of GOs on the activation energy of TGDDM/DDS system, kinetic analysis of dynamic DSC results was carried out. During a cure reaction, the reaction rate $(\mathrm{d} \alpha / \mathrm{d} t)$ as a function of time $(t)$ was calculated from the measured heat flow $(\mathrm{d} H / \mathrm{d} t)$ in dynamic DSC experiments, by Equation (1):

$$
\frac{\mathrm{d} \alpha}{\mathrm{d} t}=\frac{\frac{\mathrm{d} H}{\mathrm{~d} t}}{\Delta H}=k(T) f(\alpha)
$$

where $T$ is the temperature, $f(\alpha)$ is the reaction model and $k(T)$ is the rate constant, which follows Arrhenius equation (see Equation (2)):

$k(T)=A \exp \left(\frac{-E_{\alpha}}{R T}\right)$

where $A$ is the pre-exponential factor, $E_{\alpha}$ is the activation energy and $R$ is the gas constant.

Thus, Equation (1) can be replaced by Equation (3):

$$
\frac{\mathrm{d} \alpha}{\mathrm{d} t}=A \exp \left(\frac{-E_{\alpha}}{R T}\right) f(\alpha)
$$

so that the modified form of Equation (3) is given (see Equation (4)):

$$
\ln \left(\frac{\mathrm{d} \alpha}{\mathrm{d} t}\right)=\ln [A f(\alpha)]-\left(\frac{E_{\alpha}}{R T}\right)
$$

It is expected that the curve of $\ln (\mathrm{d} \alpha / \mathrm{d} t)$ versus $(1 / T)$ would be a straight line with slope $E_{\alpha} / R$ and an intercept of $\ln [A f(\alpha)]$. The data points for each straight line were obtained from dynamic DSC 

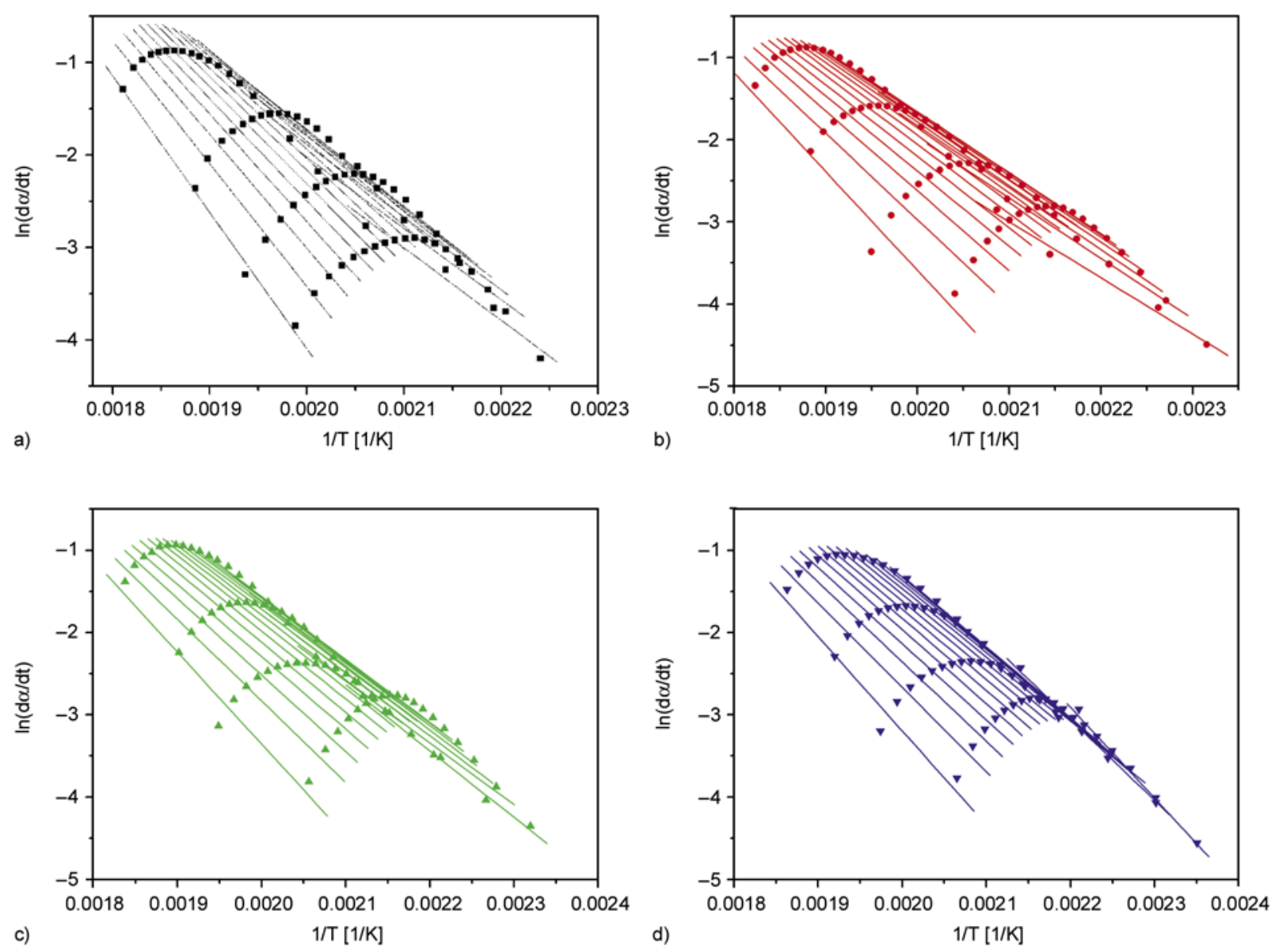

Figure 5. $\ln (\mathrm{d} \alpha / \mathrm{d} t)$ versus $1 / T$ curves for (a) neat epoxy, (b) $1 \mathrm{wt} \%$ GO/epoxy, (c) $2 \mathrm{wt} \%$ GO/epoxy, (d) $5 \mathrm{wt} \%$ GO/epoxy nanocomposites

curves at different heating rates considering same fractional conversion of reaction $(\alpha)$. By repeating the procedure, the values of $E_{\alpha}$ and $\ln [A f(\alpha)]$ corresponding to different $\alpha$ were acquired. Figure 5 presents the curves of $\ln (\mathrm{d} \alpha / \mathrm{d} t)$ versus $(1 / T)$ for the neat epoxy and the GO/epoxy nanocomposites, respectively. A set of $\alpha$ was considered from the full range of experimental data, i.e. $\alpha=0.05,0.10,0.15$, .., 0.90 and 0.95 . Using linear regression method on each set of data linked to a particular $\alpha$, the values of $E_{\alpha}$ and $\ln [A f(\alpha)]$ were obtained.

Figure 6 shows the curve of $E_{\alpha}$ versus $\alpha$ for the neat epoxy and the GO/epoxy nanocomposites. From the figures it can be seen that for the neat epoxy increases gradually with during the whole curing process whereas $E_{\alpha}$ increases significantly when $\alpha$ is higher than 0.55 , which can be regarded as gel point of the TGDDM/DDS system [38]. Due to the catalytic effect of hydroxyls on the surface of GOs, the incorporation of GOs greatly decreases the activation energy of the neat epoxy during the whole

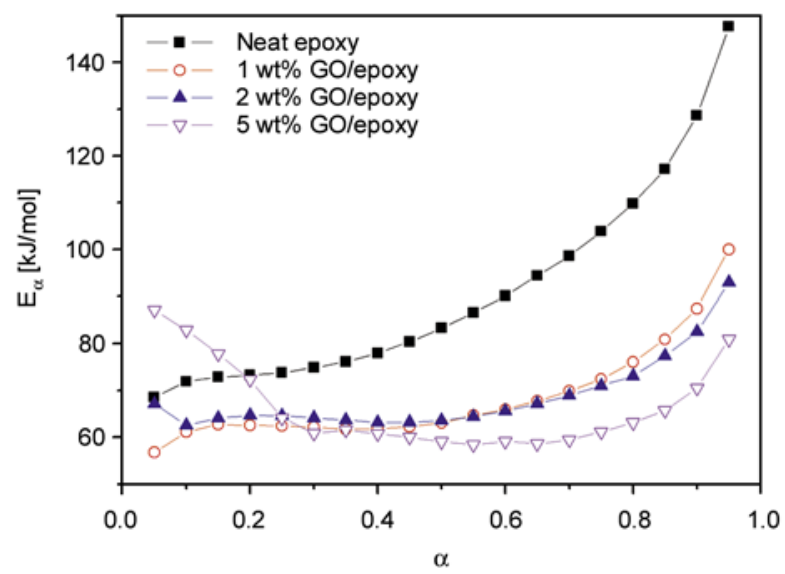

Figure 6. $E_{\alpha}$ as a function of $\alpha$ for the neat epoxy and GO/ epoxy nanocomposites. Straight lines are given only for showing the tendency

curing process except for the initial stage of $5 \mathrm{wt} \%$ GO/epoxy nanocomposites $(\alpha<0.2)$. Furthermore, $E_{\alpha}$ of $\mathrm{GO} /$ epoxy nanocomposites decrease with the increase of GO content when conversion is greater than 0.5 , indicating that higher contents of hydroxyl groups accelerate the interaction between the active 
reactants in the stage of diffusion control. Namely, the oxygen functionalities of GOs significantly hinder the occurrence of vitrification (diffusion control) of epoxy. In addition, the hindering effect increases with the increase of GO contents due to the increase of hydroxyl groups on the GOs.

\subsection{Effects of GOs on the thermal stability}

Figure $7 \mathrm{a}$ shows the TGA curves of GO and its epoxy nanocomposites, together with their derivative (i.e. the so-called differential thermogravimetric (DTG) curves, shown in Figure $7 b$ ). For GO, the main mass loss $(\sim 30 \%)$ takes place around $200^{\circ} \mathrm{C}$ and is ascribed to the decomposition of labile oxygen functional groups present in the material. There is also a mass loss $(\sim 15 \%)$ below $100^{\circ} \mathrm{C}$ attributed to the removal of adsorbed water and a slower, steady mass loss $(\sim 20 \%)$ over the whole temperature range above $300^{\circ} \mathrm{C}$, which can be assigned to the removal of more stable oxygen functionalities. These results agree well with previous reports in the literature for graphite oxide [28, 29]. The initial decomposition temperature (IDT), which is assumed to the temperature of $5 \mathrm{wt} \%$ weight loss, is shown in Table 2. As observed, the addition of GO decreases the IDT of epoxy, which indicates that the

Table 2. TGA and DTG results for GO and its epoxy nanocomposites

\begin{tabular}{|c|c|c|c|}
\hline $\begin{array}{c}\mathbf{G O} \\
{[\mathbf{w t} \% \mathbf{]}}\end{array}$ & $\begin{array}{c}\mathbf{I D T} \\
{\left[{ }^{\mathbf{}} \mathbf{C}\right]}\end{array}$ & $\begin{array}{c}\mathbf{T}_{\max } \\
{\left[{ }^{\circ} \mathbf{C}\right]}\end{array}$ & $\begin{array}{c}\text { Residue at } \mathbf{5 8 0}^{\circ} \mathbf{C} \\
{[\mathbf{\%}]}\end{array}$ \\
\hline 100 & 46.7 & 220.0 & 51.2 \\
\hline 0 & 333.3 & 404.1 & 24.4 \\
\hline 1 & 331.1 & 404.7 & 22.5 \\
\hline 2 & 322.2 & 404.4 & 23.4 \\
\hline 5 & 281.5 & 405.0 & 25.3 \\
\hline
\end{tabular}

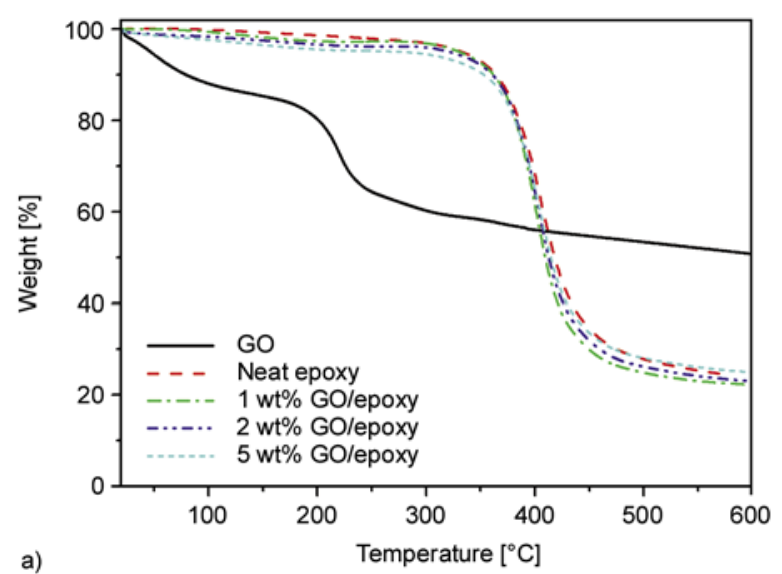

existence of GO with oxygen functionalities decreases the thermal stability of epoxy resin, and the IDT of the GO/epoxy nanocomposites decreases the increase of GO contents. Furthermore, it can also be observed that the residues at $580^{\circ} \mathrm{C}$ increase with the rise of GO contents, because of the more carbon-based nanofillers in the nanocomposites.

As can be seen in the DTG curves (Figure 7b), the thermal degradation of neat epoxy and GO/epoxy nanocomposites are characterized by a single stage, indicating the addition of GOs has no influence on decomposition process. For GO/epoxy nanocomposites, the main mass loss $(\sim 30 \%)$ around $200^{\circ} \mathrm{C}$ of GO disappears, suggesting a good interaction between oxygen functional groups and epoxy. Furthermore, the temperatures of maximum rate of degradation for epoxy and its GO nanocomposites remain fairly constant.

\subsection{Dispersion of GOs in epoxy resin}

Because of epoxide groups in the chemical structures, compatibility of GOs with epoxy and dispersion in the matrix were sigifcantly improved. Figure 8 shows the fracture micrographs of several freeze-fractured specimens. Fine dispersion of GO in the epoxy is observed. Some irregular protuberances are observed on the composite surface and furthermore, their number increases with increasing GO content. The length and thickness of these protuberances are in a scale range from hundreds of nanometers to several microns. The uniform dispersion of GOs in the epoxy matrix results in a strong catalytic effect by the hydroxyls on the GOs lowers activation energy and decreases the thermal stability of epoxy.

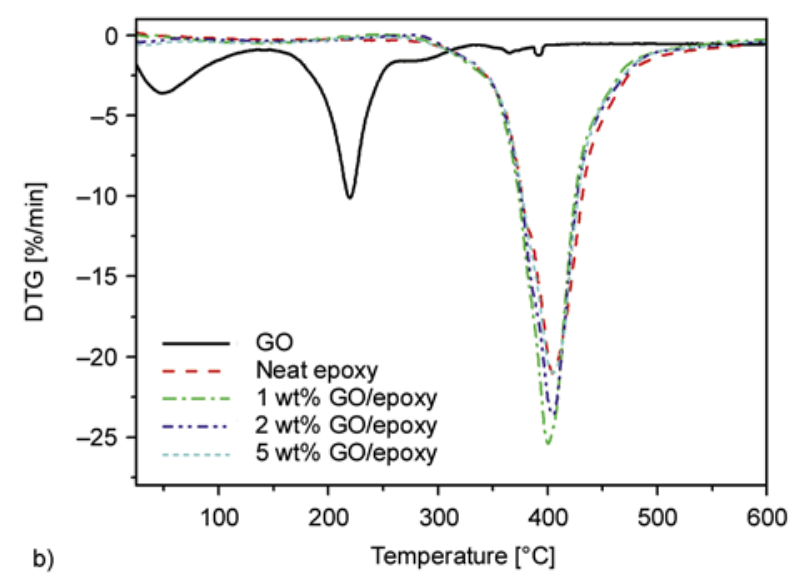

Figure 7. TGA (a) and DTG (b) curves of GOs and GO/epoxy nanocomposites 


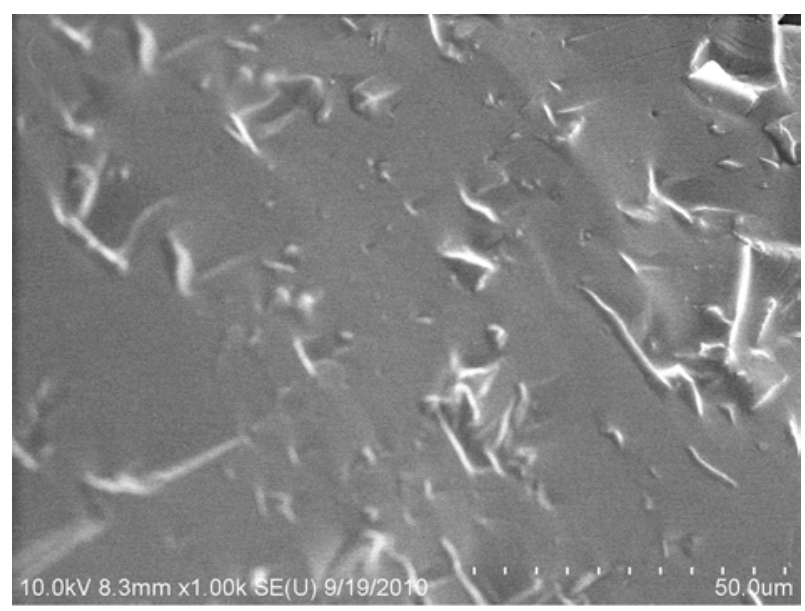

a) 1 wt \% GO/epoxy

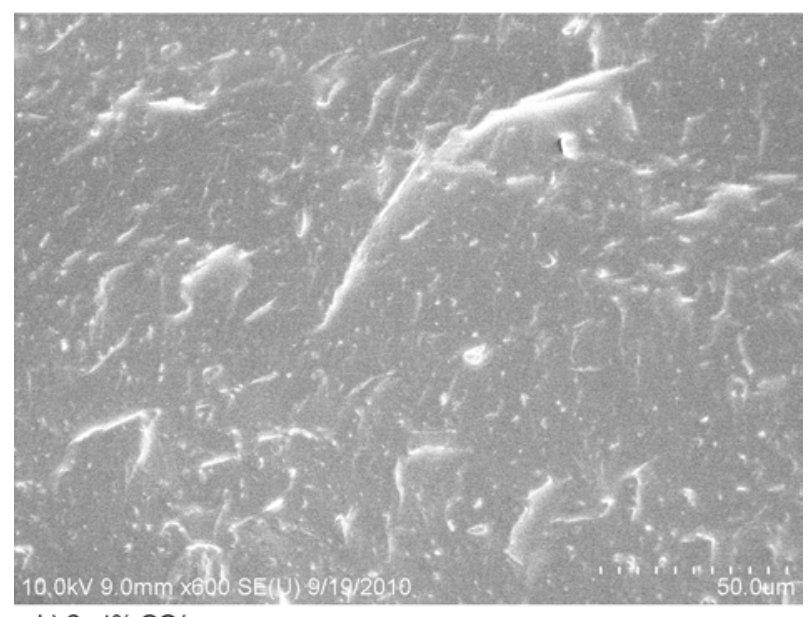

b) 2 wt\% GO/epoxy

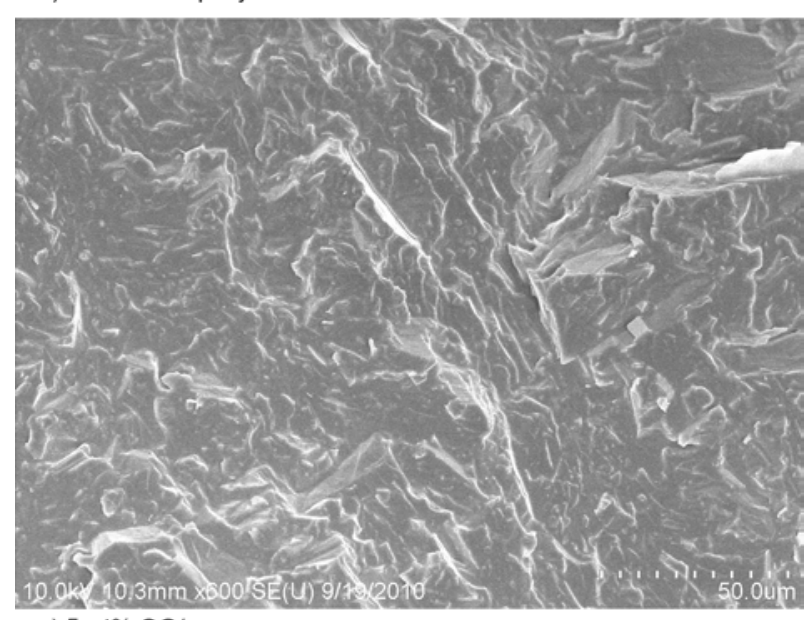

c) 5 wt\% GO/epoxy

Figure 8. SEM fracture micrographs of GO/epoxy nanocomposites: (a) $1 \mathrm{wt} \%$, (b) $2 \mathrm{wt} \%$ and (c) $5 \mathrm{wt} \%$ after quenching in liquid nitrogen

\section{Conclusions}

The effects of GOs on the cure reaction, thermal stability and morphology of TGDDM/DDS epoxy resin were investigated with dynamic DSC, TGA and SEM. Curing reactions with four different heating rates were analyzed. Furthermore, the functional groups on the surface of GOs were studied with XPS and FT-IR. XPS and FT-IR results showed the presence of different types of oxygen functionalities on the GO. The conversion of cure reaction versus temperature curves in each epoxy system showed the sigmoidal shape, which indicated that the GOs did not change the autocatalytic curing mechanism of TGDDM/DDS system. With the increase of GO content, the initial reaction temperature and exothermal peak temperature decreased. Moreover, the incorporation of GOs increased the enthalpies of the cure reaction. Results on the $\mathrm{GO} /$ epoxy systems from the activation energy method indicated that the activation energies were all lower than that of the neat epoxy during the whole curing process, except for the lower conversion of $5 \mathrm{wt} \%$ $\mathrm{GO} /$ epoxy system $(\alpha<0.2)$. For GO/epoxy nanocomposites, $E_{\alpha}$ increased with the increase of GO contents in the initial stage of curing process. However, $E_{\alpha}$ decreased with the increase of GO contents in the latter stage, which indicated that the hindering effect of vitrification for GO/epoxy nanocomposites increased with the increase of GO contents. Therefore, it can be concluded that different types of oxygen functionalities on the surface of the GOs in epoxy significantly catalyzed the cure reaction of the curing process. Furthermore, the catalytic effect increased with the increase of GO contents. The addition of GO decreased the initial decomposition temperature of epoxy, which suggested the existence of GO decreased the thermal stability of epoxy. SEM results showed that GOs was uniformly dispersed in the epoxy due to the existence of epoxide groups on the surface of GOs.

\section{References}

[1] Opalički M., Kenny J. M., Nicolais L.: Cure kinetics of neat and carbon-fiber-reinforced TGDDM/DDS epoxy systems. Journal of Applied Polymer Science, 61, 1025-1037 (1996).

DOI: 10.1002/(SICI)1097-4628(19960808)61:6<1025 $\because$ AID-APP17>3.0.CO;2-V

[2] Zhou Y. X., Wu P. X., Cheng Z-Y., Ingram J., Jeelani S.: Improvement in electrical, thermal and mechanical properties of epoxy by filling carbon nanotube. Express Polymer Letters, 2, 40-48 (2008).

DOI: $10.3144 /$ expresspolymlett.2008.6 
[3] Romhány G., Szebényi G.: Interlaminar crack propagation in MWCNT/fiber reinforced hybrid composites. Express Polymer Letters, 3, 145-151 (2009). DOI: 10.3144/expresspolymlett.2009.19

[4] Xie H. F., Liu C. G., Yuan Z. R., Yang H., Wang Z. L., Cheng R. S.: Thermoanalytical studies of high performance epoxy/carbon nanotube composites. Acta Polymerica Sinica, 4, 332-336 (2008).

DOI: $10.3724 /$ SP.J.1105.2008.00332

[5] Spitalsky Z., Tasis D., Papagelis K., Galiotis C.: Carbon nanotube-polymer composites: Chemistry, processing, mechanical and electrical properties. Progress in Polymer Science, 35, 357-401 (2010).

DOI: 10.1016/j.progpolymsci.2009.09.003

[6] Compton O. C., Nguyen S. T.: Graphene oxide, highly reduced graphene oxide, and graphene: Versatile building blocks for carbon-based materials. Small, 6, 711723 (2010).

DOI: $10.1002 /$ smll.200901934

[7] Dreyer D. R., Park S., Bielawski C. W., Ruoff R. S.: The chemistry of graphene oxide. Chemical Society Reviews, 39, 228-240 (2010).

DOI: $10.1039 / \mathrm{b} 917103 \mathrm{~g}$

[8] Zhu Y., Murali S., Cai W., Li X., Suk J. W., Potts J. R., Ruoff R. S.: Graphene and graphene oxide: Synthesis, properties, and applications. Advanced Materials, 22, 3906-3924 (2010).

DOI: $10.1002 / \mathrm{adma} .201001068$

[9] Kim H., Abdala A. A., Macosko C. W.: Graphene/ polymer nanocomposites. Macromolecules, 43, 65156530 (2010).

DOI: $10.1021 / \mathrm{ma100572 \textrm {e }}$

[10] Potts J. R., Dreyer D. R., Bielawski C. W., Ruoff R. S.: Graphene-based polymer nanocomposites. Polymer, 52, 5-25 (2011). DOI: 10.1016/j.polymer.2010.11.042

[11] Cai W., Piner R. D., Stadermann F. J., Park S., Shaibat M. A., Ishii Y., Yang D., Velamakanni A., An S. J., Stoller M., An J., Chen D., Ruoff R. S.: Synthesis and solid-state NMR structural characterization of ${ }^{13} \mathrm{C}$ labeled graphite oxide. Science, 321, 1815-1817 (2008).

DOI: 10.1126/science.1162369

[12] Yang H., Shan C., Li F., Zhang Q., Han D., Niu L.: Convenient preparation of tunably loaded chemically converted graphene oxide/epoxy resin nanocomposites from graphene oxide sheets through two-phase extraction. Journal of Materials Chemistry, 19, 8856-8860 (2009).

DOI: $10.1039 / \mathrm{b} 915228 \mathrm{~h}$

[13] Menczel J. D., Judovits L., Prime R. B., Bair H. E., Reading M., Swier S.: Differential scanning calorimetry (DSC). in 'Thermal analysis of polymers: Fundamentals and applications' (eds. Menczel J. D., Prime R. B.) Wiley, New Jersey, 130-154 (2009).

DOI: $10.1002 / 9780470423837 . c h 2$
[14] Xie H., Liu B., Sun Q., Yuan Z., Shen J., Cheng R.: The influence of vapor-grown carbon fibers on the cure reaction of epoxy and the curing kinetics of the composites (in Chinese). Acta Polymerica Sinica, 2005, 891-895 (2005).

[15] Bae J., Jang J., Yoon S-H.: Cure behavior of the liquidcrystalline epoxy/carbon nanotube system and the effect of surface treatment of carbon fillers on cure reaction. Macromolecular Chemistry and Physics, 203, 2196-2204 (2002).

DOI: 10.1002/1521-3935(200211)203:15<2196::AIDMACP2196>3.0.CO;2-U

[16] Allaoui A., El Bounia N.: How carbon nanotubes affect the cure kinetics and glass transition temperature of their epoxy composites? - A review. Express Polymer Letters, 3, 588-594 (2009).

DOI: $10.3144 /$ expresspolymlett.2009.73

[17] Xie H. F., Liu B. H., Yuan Z. R., Shen J. Y., Cheng R. S.: Cure kinetics of carbon nanotube/tetrafunctional epoxy nanocomposites by isothermal differential scanning calorimetry. Journal of Polymer Science Part B: Polymer Physics, 42, 3701-3712 (2004).

DOI: $10.1002 /$ polb.20220

[18] Xie H., Liu B., Sun Q., Yuan Z., Shen J., Cheng R.: Cure kinetic study of carbon nanofibers/epoxy composites by isothermal DSC. Journal of Applied Polymer Science, 96, 329-335 (2005).

DOI: 10.1002/app.21415

[19] Abdalla M., Dean D., Robinson P., Nyairo E.: Cure behavior of epoxy/MWCNT nanocomposites: The effect of nanotube surface modification. Polymer, 49, 33103317 (2008).

DOI: $10.1016 /$ j.polymer.2008.05.016

[20] Zhou T., Wang X., Liu X., Xiong D.: Influence of multi-walled carbon nanotubes on the cure behavior of epoxy-imidazole system. Carbon, 47, 1112-1118 (2009).

DOI: $10.1016 /$ j.carbon.2008.12.039

[21] Zhou T., Wang X., Wang T.: Cure reaction of multiwalled carbon nanotubes/diglycidyl ether of bisphenol A/2-ethyl-4-methylimidazole (MWCNTs/DGEBA/ EMI-2,4) nanocomposites: Effect of carboxylic functionalization of MWCNTs. Polymer International, 58, 445-452 (2009).

DOI: $10.1002 / \mathrm{pi} .2558$

[22] Zhou T., Wang X., Liu X. H., Lai J. Z.: Effect of silane treatment of carboxylic-functionalized multi-walled carbon nanotubes on the thermal properties of epoxy nanocomposites. Express Polymer Letters, 4, 217-226 (2010).

DOI: $10.3144 /$ expresspolymlett.2010.28

[23] Jana S., Zhong W-H.: Curing characteristics of an epoxy resin in the presence of ball-milled graphite particles. Journal of Materials Science, 44, 1987-1997 (2009).

DOI: $10.1007 / \mathrm{s} 10853-009-3293-2$ 
[24] Guo B., Wan J., Lei Y., Jia D.: Curing behaviour of epoxy resin/graphite composites containing ionic liquid. Journal of Physics D: Applied Physics, 42, 145307/1-145307/8 (2009).

DOI: $10.1088 / 0022-3727 / 42 / 14 / 145307$

[25] Gerson A. L., Bruck H. A., Hopkins A. R., Segal K. N.: Curing effects of single-wall carbon nanotube reinforcement on mechanical properties of filled epoxy adhesives. Composites Part A: Applied Science and Manufacturing, 41, 729-736 (2010).

DOI: $10.1016 /$ j.compositesa.2010.02.002

[26] May C. A.: Epoxy resins, chemistry and technology. Marcel Dekker, New York (1988).

[27] Hummers W. S., Offeman R. E.: Preparation of graphitic oxide. Journal of the American Chemical Society, 80, 1339 (1958). DOI: $10.1021 / \mathrm{ja} 01539 \mathrm{a} 017$

[28] Stankovich S., Dikin D. A., Piner R. D., Kohlhaas K. A., Kleinhammes A., Jia Y. Y., Wu Y., Nguyen S. T., Ruoff R. S.: Synthesis of graphene-based nanosheets via chemical reduction of exfoliated graphite oxide. Carbon, 45, 1558-1565 (2007). DOI: $10.1016 /$ j.carbon.2007.02.034

[29] Paredes J. I., Villar-Rodil S., Martínez-Alonso A., Tascón J. M. D.: Graphene oxide dispersions in organic solvents. Langmuir, 24, 10560-10564 (2008). DOI: $10.1021 / 1 \mathrm{a} 801744 \mathrm{a}$

[30] Du X., Yu Z-Z., Dasari A., Ma J., Mo M., Meng Y., Mai Y-W.: New method to prepare graphite nanocomposites. Chemistry of Materials, 20, 2066-2068 (2008). DOI: $10.1021 / \mathrm{cm} 703285 \mathrm{~s}$

[31] Kim S. H., Woo I. L., Park J. M.: Assessment of dispersion in carbon nanotube reinforced composites using differential scanning calorimetry. Carbon, 47, 2699-2703 (2009). DOI: $10.1016 /$ j.carbon.2009.05.026
[32] Xie H., Liu B., Yang H., Wang Z., Shen J., Cheng R. S.: Thermal characterization of carbon-nanofiberreinforced tetraglycidyl-4,4'-diaminodiphenylmethane/4,4'-diaminodiphenylsulfone epoxy composites. Journal of Applied Polymer Science, 100, 295298 (2006). DOI: $10.1002 / a p p .23106$

[33] Seyhan A. T., Sun Z., Deitzel J., Tanoglu M., Heider D.: Cure kinetics of vapor grown carbon nanofiber (VGCNF) modified epoxy resin suspensions and fracture toughness of their resulting nanocomposites. Materials Chemistry and Physics, 118, 234-242 (2009). DOI: 10.1016/j.matchemphys.2009.07.045

[34] Cai Z-Q., Movva S., Chiou N-R., Guerra D., Hioe Y., Castro J. M., Lee J. L.: Effect of polyaniline surface modification of carbon nanofibers on cure kinetics of epoxy resin. Journal of Applied Polymer Science, 118, 2328-2335 (2010).

DOI: $10.1002 /$ app.31656

[35] Rozenberg B. A.: Kinetics, thermodynamics and mechanism of reactions of epoxy oligomers with amines. Advances in Polymer Science, 75, 113-165 (1986). DOI: $10.1007 / \mathrm{BFb} 0017916$

[36] He H., Klinowski J., Forster M., Lerf A.: A new structural model for graphite oxide. Chemical Physics Letters, 287, 53-56 (1998).

DOI: $10.1016 / \mathrm{S} 0009-2614(98) 00144-4$

[37] Gao W., Alemany L. B., Ci L., Ajayan P. M.: New insights into the structure and reduction of graphite oxide. Nature Chemistry, 1, 403-408 (2009).

DOI: $10.1038 /$ nchem.281

[38] Gao J., Shen K., Gao Z. M.: The cure behavior of tetraglycidyl diaminodiphenyl methane with diaminodiphenyl sulfone. Thermochimica Acta, 352-353, 153-158 (2000). DOI: $10.1016 / \mathrm{S} 0040-6031(99) 00460-8$ 